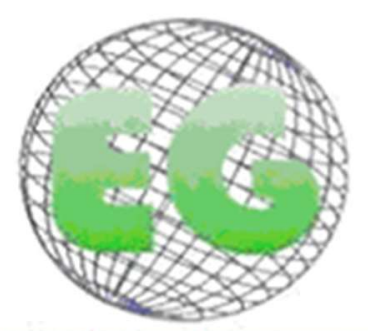

ISSN 1695-6141

\title{
ORIGINALES
}

\section{Factores relacionados con la adherencia al tratamiento antirretroviral en mujeres con VIH: Un estudio mixto con diseño secuencial}

Factors affecting adherence to antiretroviral treatment in women with HIV: A sequential mixed model research design

\author{
Sara Sánchez Peña ${ }^{1}$ \\ María del Mar Pastor Bravo² \\ Miguel Ángel Cánovas Tomás ${ }^{3}$ \\ Pilar Almansa Martínez ${ }^{2}$ \\ Caridad Peñalver Guillén ${ }^{1}$ \\ Ismael Jiménez-Ruiz ${ }^{2}$
}

\begin{abstract}
${ }^{1}$ Servicio Murciano de Salud. Murcia. España.
${ }^{2}$ Departamento de Enfermería. Universidad de Murcia. Grupo de investigación Enfermería, mujer y cuidados. IMIB-Arrixaca. Murcia. España. mariadelmarpastorbravo@gmail.com

${ }_{3}^{3}$ Departamento de Enfermería. Universidad de Murcia. Grupo de investigación Enfermería, mujer y cuidados. Murcia. España.
\end{abstract}

\section{https://doi.org/10.6018/eglobal.437711}

Recibido: $20 / 07 / 2020$

Aceptado: $25 / 09 / 2020$

\section{RESUMEN:}

Introducción: EI VIH/Sida afecta cada vez a más mujeres. La adherencia al tratamiento antirretroviral es decisiva en la calidad de vida de las personas infectadas.

Objetivos: El objetivo del estudio es determinar el grado de adherencia manifestada en un grupo de mujeres con $\mathrm{VIH} / \mathrm{Sida}$, con TAR e identificar los factores y circunstancias que influyen en su adherencia.

Metodología: Se ha realizado un estudio con diseño mixto secuencial explicativo. Los sujetos de estudio son 86 mujeres diagnosticadas con $\mathrm{VIH} /$ Sida en tratamiento con TARGA.

Resultados: Se recogieron datos cualitativos de 18 de ellas. El $59,3 \%$ de las participantes son no adherentes. Los factores determinantes de la no adherencia son el grado académico, edad, ingresos, así como factores personales, interpersonales como el apoyo sociofamiliar, estigma percibido y autoestigma y factores relativos a la enfermedad y tratamiento.

Conclusión: Los cuidados de enfermería deben abordar con enfoque de género aquellos factores psicosociales e individuales del proceso de adherencia.

Palabras claves: Infecciones por $\mathrm{VIH}$; $\mathrm{VIH}$; antirretrovirales; cumplimiento y adherencia al tratamiento; salud de la mujer; metodología mixta. 


\begin{abstract}
:
Background: HIVIAIDS is affecting more and more women. Adherence to antiretroviral treatment (ART) is decisive for those infected to achieve quality of life.

Purpose: The aim of the present study is to determine the degree of adherence displayed by a group of women with HIVIAIDS and to identify those factors and circumstances which might influence their adherence to ART.

Method: A sequential mixed model research design was applied. The subjects studied consisted of 86 women diagnosed with HIVIAIDS and treated with ART.

Findings and discussion: Qualitative data were collected from 18 of these women. $59.3 \%$ of participants were non-adherents. The determining factors for non-adherence were level of education, age, income, as well as personal and/or interpersonal factors such as socio-familial support, perceived stigma, self-stigma and factors related to disease and treatment. Nursing care should take a genderfocused approach towards those psychological and personal factors inherent in the adherence process.
\end{abstract}

Key words: HIV Infections; HIV; Anti-Retroviral Agents; Treatment Adherence and Compliance; Women's Health; mixed methods.

\title{
INTRODUCCIÓN
}

La infección del VIH/Sida se ha convertido en una pandemia de consecuencias severas para la humanidad, afectando a la vida de 36,6 millones de personas ${ }^{(1)}$. En sus inicios, la epidemia afectaba mayoritariamente a los hombres, pero los datos actuales reflejan que un $57 \%$ de las personas infectadas por $\mathrm{VIH} /$ Sida son mujeres ${ }^{(2)}$.

Desde el inicio de la epidemia se han notificado en España un total de 85.720 casos, donde la infección por VIH se transmite mayoritariamente por vía sexual. La incidencia en la Región de Murcia es inferior a la media del conjunto estatal para todo el periodo 2009-2015, pero superior a la incidencia media en los países de la Unión Europea/ Europa Occidental ${ }^{(3,4)}$. Respecto al grupo de las mujeres diagnosticadas de $\mathrm{VIH}$, el $89 \%$ de los casos en la Región de Murcia son atribuibles a transmisión heterosexual y el $5 \%$ al uso de drogas inyectadas ${ }^{(3)}$.

En la era de la terapia antirretroviral, el $\mathrm{VIH}$ ha pasado a ser una enfermedad crónica, donde la adherencia (ADH) al tratamiento antirretroviral (TAR), adquiere gran importancia por su repercusión en el sistema inmunológico y la calidad de vida de las personas infectadas con el $\mathrm{VIH}^{(5)}$. Existen por ello, numerosos estudios que plantean la necesidad de explorar y considerar los contextos sociales de las personas con TAR a fin de hacer las adaptaciones pertinentes y favorecer una correcta $\operatorname{ADH}^{(6,7)}$. En este sentido, las intervenciones deben planificarse y diseñarse para que se puedan adaptar a las necesidades de subgrupos específicos, teniendo en cuenta aspectos socioculturales y el apoyo social, y aplicando un factor de género para tener en cuenta la vulnerabilidad específica hacia la transmisión y el desarrollo de la enfermedad(8,9).

Las mujeres con $\mathrm{VIH}$ experimentan múltiples formas de discriminación tanto por su estado como por motivos de su sexo y son estigmatizadas por la vía de transmisión ${ }^{(10)}$, vinculando el estigma con el aislamiento y la soledad(11). Enfatizar en la eliminación de los conflictos que generan los procesos de discriminación como la exclusión social y la marginación a las personas seropositivas del ámbito laboral, educativo y social(12) precisa de estudios que aborden el fenómeno de una forma completa. Las razones por las que no se logra mejorar la ADH se debe a que la mayoría de las pautas de ADH a TAR se basan en estudios cuantitativos con directrices centradas en el individuo, excluyendo las comunidades donde viven estas personas $^{(6)}$. Por ello el objetivo principal planteado en el presente estudio es 
determinar el grado de adherencia manifestada en un grupo de mujeres con VIH/Sida, con TAR e identificar y analizar los factores y circunstancias que influyen en la ADH en dichas mujeres

\section{METODOS}

\section{Diseño}

Estudio mixto con diseño secuencial explicativo que se inicia con la recogida y análisis de los datos cuantitativos, para continuar con la recogida y análisis de los datos cualitativos en igualdad de estatus, finalizando con una interpretación de los resultados en la que se establecen relaciones entre los datos cualitativos y cuantitativos.

\section{Población de estudio y muestreo}

Se trata de un estudio multicéntrico realizado en seis hospitales públicos de seis Áreas de Salud de la Región de Murcia, España. Para la conformación de la muestra se pautaron como criterios de inclusión: ser mujer de entre 18 y 65 años, tener un diagnóstico de VIH/SIDA, tiempo de tratamiento con TARGA de al menos 6 meses, acudir de forma periódica a revisiones clínicas en hospital de referencia. Como criterios de exclusión se planteó: la existencia de barrera idiomática, tener un diagnóstico de deterioro cognitivo avanzado, estar ingresada o embaraza en el momento del estudio.

El muestreo fue probabilístico para la fase cuantitativa y el tamaño de la muestra se estableció de acuerdo con las pacientes que acudieron personalmente a recoger la medicación de la farmacia hospitalaria de los hospitales durante los años 2014-2015. De esta forma la población total del estudio se compone de 86 mujeres que satisfacen los criterios descritos anteriormente.

La población de la fase cualitativa estuvo compuesta por 15 mujeres entre 18-65 años, participantes en la fase cuantitativa y que recogieron su medicación en la farmacia hospitalaria durante 2015. Se incorporaron participantes por muestreo intencional hasta llegar a la saturación de datos.

\section{Fase cuantitativa}

Esta fase tiene un diseño descriptivo, transversal y retrospectivo. Es transversal para las variables: factores que influyen en la no ADH en las mujeres con TAR y Grado de ADH manifestada por las mujeres con TAR. Y es retrospectivo para la variable Grado de $A D H$ según el registro de dispensación de la farmacia hospitalaria (FH). Para la obtención de los datos de la fase cuantitativa se utilizaron los siguientes instrumentos:

1. CAT-M VIH(13), está conformado por respuestas cerradas, dicotómicas y/o múltiples y consta de tres apartados: Datos sociodemográficos, historia de la enfermedad y comportamiento de adherencia al tratamiento.

2. Cuestionario sobre adherencia SMAQ. Contiene seis preguntas con respuesta cerrada y considera al paciente adherente a aquel que tiene un cumplimiento 
terapéutico igual o superior al $95 \%(14,15)$. Este instrumento ha sido validado en la población española(16).

3. Pruebas analíticas: se recabaron de las historias clínicas los resultados de la carga viral como medida indirecta de adherencia al TAR y refuerzo de la misma(17), así como para confirmar la sospecha de un cumplimiento terapéutico deficiente ${ }^{(18)}$; y el recuento de CD4/CD8 para estadificar la infección por $\mathrm{VIH}$, la necesidad de su profilaxis, y la eventual discontinuación ${ }^{(19)}$.

4. Registro de dispensación de TAR desde la farmacia hospitalaria: aporta información sobre la retirada de la medicación de la paciente en la farmacia hospitalaria y permite conocer la continuidad de los tratamientos, así como de los cambios a las nuevas combinaciones de $\operatorname{TAR}^{(14)}$.

\section{Fase cualitativa}

El diseño cualitativo es interpretativo fenomenológico para comprender la experiencia de las mujeres que viven con el $\mathrm{VIH} /$ Sida, construyendo a través de la particularidad de las vivencias una experiencia del grupo que vive una misma realidad. En esta fase se utilizó la observación participante y selectiva durante las entrevistas en profundidad, anotándose en un cuaderno de campo los resultados para relacionar e interpretar sus significados y el método conversacional a través de una entrevista semiestructurada, con los temas de interés que se pretendían explorar. Las preguntas fueron contrastadas previamente con los informantes clave y expertos en la materia. La entrevista fue conversacional, no directiva, sin juicios de valor, flexible para adaptarse al discurso de cada mujer con la finalidad de que la entrevistada descubra a través de la fenomenología, las motivaciones que incentivan su comportamiento. Las entrevistas fueron realizadas en una sala multiusos en los servicios de captación de participantes en un ambiente de privacidad, cordial y tranquilo. La duración media de las entrevistas fue de 45 minutos.

\section{Análisis de datos}

Para el análisis de los datos cuantitativos se emplearon métodos descriptivos básicos. La comparación entre grupos para las variables cualitativas se realizó mediante la prueba Chi-cuadrado. Para determinar el grado de acuerdo entre los métodos empleados para la clasificación de las pacientes según la adherencia se calculó el índice Kappa. El análisis estadístico se realizó con el programa SPSS 23.0 para Windows. Las diferencias consideradas estadísticamente significativas son aquellas cuya $p<0.05$. Mientras que para el análisis de los datos cualitativos se partió del análisis de contenido latente. Las fases del análisis fueron cuatro: Transcripción textual de las entrevistas, la organización y procesamiento de los datos mediante la identificación de unidades de registro y las unidades de contexto, la reducción de los datos a través de la reagrupación de todos los códigos que compartían significado, identificándose categorías y subcategorías y la exposición de los datos a través de la búsqueda de relaciones intergrupo y entre los grupos de significado entre sí. Posteriormente se realizó un proceso en el que se compararon, incorporaron e integraron los datos procedentes de ambos métodos, de modo que, durante la interpretación, los datos cualitativos ayudaron a explicar y complementar a los cuantitativos. 


\section{Consideraciones éticas}

Durante el proceso de recogida de datos se les facilitó toda la información precisa y adaptada al contexto social y nivel cultural de las participantes. Además, se les ofreció la posibilidad de no hablar de un determinado tema, o la opción de interrumpir en cualquier momento la entrevista sin ningún perjuicio. Las participantes firmaron el "Consentimiento Informado". Del mismo modo, se les pidió permiso para utilizar el grabador de voz, tras la transcripción, los audios fueron destruidos.

El estudio cuenta con la aprobación de los Comités de Ética e Investigación Clínica de la Universidad de Murcia y de los Hospitales en los que se recogieron los datos.

\section{Criterios de rigor}

La credibilidad, transferibilidad y confirmabilidad se aplicaron como criterios de calidad para asegurar la rigurosidad de la investigación. En este sentido, la veracidad y la credibilidad de la información fue confirmada mediante la corroboración por expertos y participantes. La transferibilidad por la transparencia y protocolización de todo el proceso; y la confirmabilidad a través de la descripción detallada de las características sociodemográficas de las informantes, así como los criterios y proceso de selección. Así mismo se realizó una triangulación de datos recabando información procedente de mujeres de diferentes zonas geográficas y núcleos asistenciales y una triangulación metodológica comparando y contrastando los resultados obtenidos mediante instrumentos cuantitativos y cualitativos.

\section{RESULTADOS}

\section{Perfil sociodemográfico de las participantes}

La muestra del estudio cuantitativo es de 86 mujeres con VIH/Sida en tratamiento con TAR y la del estudio cualitativo es una submuestra del cuantitativo de 15 mujeres con problemas de adherencia a dicho tratamiento. Las participantes tienen edades comprendidas entre los 20 y 65 años y una edad media de 45,5 años para la muestra cuantitativa y una media de 42,2 para la cualitativa.

Como se observa en la tabla 1, las participantes de la muestra cuantitativa tienen un nivel de estudios mayoritario de primaria seguido de secundaria/bachiller, el $45 \%$ se encuentran en activo, 35 tiene hijos a su cargo y 77 se encargan de las labores domésticas. Por otro lado, el perfil de las participantes con problemas de adherencia (fase cualitativa) se conforma en torno una mujer con estudios de nivel básico, con recursos económicos bajos (500-700€/mes) y con trabajos remunerados (10 participantes con actividad laboral reconocida) que concilian con las tareas del hogar (14). 
Tabla 1. Características sociodemográficas

\begin{tabular}{|c|c|c|}
\hline Caracteristicas & $\mathrm{N}=86(\%)$ estudio cuantitativo & $\mathrm{N}=15(\%)$ estudio cualitativo \\
\hline \multicolumn{3}{|l|}{ Estado civil } \\
\hline Sin pareja & $15(17,4)$ & $2(13,3)$ \\
\hline Casada & $20(23,3)$ & $1(6,6)$ \\
\hline Viuda & $14(16,3)$ & $4(26,6)$ \\
\hline Divorciada & $17(19,8)$ & $2(13,3)$ \\
\hline Con pareja & $20(23,3)$ & $6(40)$ \\
\hline \multicolumn{3}{|l|}{ Convivencia } \\
\hline Con la pareja & $24(27,9)$ & $7(46,6)$ \\
\hline Con la pareja e hijos & $17(19,8)$ & $1(6,6)$ \\
\hline Con los padres & $7(8,1)$ & $2(13,3)$ \\
\hline Con los hijos & $21(24,4)$ & $4(26,6)$ \\
\hline En solitario & $17(19,8)$ & $1(6,6)$ \\
\hline \multicolumn{3}{|l|}{ Nivel de estudios } \\
\hline Sin estudios & $18(20,9)$ & $3(20)$ \\
\hline Estudios Primarios & $34(39,5)$ & $5(33,3)$ \\
\hline Secundaria/Bachiller & $28(32,6)$ & $5(33,3)$ \\
\hline Universitarios & $6(7)$ & $2(13,3)$ \\
\hline \multicolumn{3}{|l|}{ Situación laboral } \\
\hline En activo & $39(45,3)$ & $10(66,6)$ \\
\hline En paro & $18(20,9$ & $3(20)$ \\
\hline Pensionista & $29(33,7)$ & $2(13,3)$ \\
\hline \multicolumn{3}{|l|}{ Ingresos propios/mes } \\
\hline Menos de $500 €$ & $39(45,3)$ & $6(40)$ \\
\hline $500-700 €$ & $23(26,7)$ & $5(33,3)$ \\
\hline Más de $700 €$ & $23(26,7)$ & $4(26,6)$ \\
\hline Nada & $1(1,2)$ & 0 \\
\hline \multicolumn{3}{|l|}{ País de origen } \\
\hline España & $68(79,1)$ & $12(80)$ \\
\hline Otros & $18(20,9 \%)$ & $3(20)$ \\
\hline Con hijos a cargo & $35(40,7)$ & $9(60)$ \\
\hline $\begin{array}{l}\text { Realizan trabajo } \\
\text { doméstico }\end{array}$ & $77(89,5)$ & $14(93,3)$ \\
\hline
\end{tabular}

\section{Resultados cuantitativos}

\section{Características clínicas y de tratamiento del VIH/Sida}

En la tabla 2, se recogen las características clínicas y de tratamiento de la enfermedad. Dentro de las características clínicas destaca que el $79,1 \%$ contrajo el VIH por transmisión sexual, el $73,3 \%$ están en un estadio A1 de la enfermedad y que el $76,7 \%$ una carga viral indetectable. 
Tabla 2. Características clínicas y de tratamiento $(\mathrm{N}=86)$

\begin{tabular}{lc}
\hline \hline Características & $\mathbf{n}(\%)$ \\
\hline Miembros familia con VIH & $10(11,6)$ \\
La pareja actual & $3(3,5)$ \\
Hijos & $32(37,2)$ \\
La pareja anterior & $6(7)$ \\
Otros & $35(40,7)$ \\
Ninguno & \\
Vía de transmisión & $68(79,1)$ \\
Sexual & $9(10,5)$ \\
Agujas u objetos corto-punzantes & $3(3,5)$ \\
Sanguínea & $6(7)$ \\
Otra & \\
Estadio de la enfermedad & $63(73,3)$ \\
A1 & $14(16,3)$ \\
A2 & $9(10,5)$ \\
A3 & $0(0 \%)$ \\
B-C & Media (DT) \\
Tratamiento TAR & $2,0(0,8)$ \\
No medicamentos (1-4 fármacos) & $3,2(0,7)$ \\
No principios activos (1-4 principios activos) & $2,6(1,4)$ \\
No pastillas/día (1-4pastillas/día) & \\
\hline \hline
\end{tabular}

En cuanto al tratamiento antirretroviral, el promedio de medicamentos administrados es de $2(\mathrm{DT}=0,8)$ con un consumo medio de $2,6(\mathrm{DT}=1,4)$ pastillas al día y un promedio de principios activos de 3,2 (DT $=0,7$ ). El $53,5 \%$ refieren efectos secundarios. Con respecto a la carga viral, existe una diferencia significativa $(p=0008)$ entre las participantes adherentes al tratamiento TAR y las no adherentes, siendo el porcentaje de pacientes con carga viral detectable no adherentes significativamente superior al de adherentes ( $33 \%$ y $8,6 \%$ respectivamente).

\section{Adherencia al tratamiento antirretroviral}

El análisis de la ADH al tratamiento TAR por medio del cuestionario SMAQ determinó que un $41,9 \%$ de las participantes infectadas por VIH fueron clasificadas como no adherentes mientras que el análisis de los registros de medicación de la farmacia hospitalaria concluyó que el $40,7 \%$ de estas participantes eran no adherentes. Lo cual establece un grado de acuerdo entre ambas herramientas del $63,95 \%$ con un índice Kappa de 0,257 $(p=0,017)$. Si una participante es no adherente por al menos uno de los dos métodos, fue clasificada como no adherente. Así el 59,3\% de las mujeres infectadas por $\mathrm{VIH}$ que participaron en el estudio resultaron no-adherentes.

\section{Factores que influyen en la no adherencia al tratamiento antirretroviral}

A nivel multivariante, las variables que mostraron un efecto significativo en la predicción de la no-ADH fueron la edad, el nivel de estudios e ingresos. A mayor edad la probabilidad de ser no adherente disminuye para las mujeres de la muestra (OR = 
0,92, $p=0,032)$. Las participantes con estudios universitarios tienen menor probabilidad de ser no adherentes que aquellas sin estudios o estudios primarios (OR $=0,10, p=0,040$ y las mujeres con ingresos propios superiores a $700 €$, tienen menor probabilidad de ser no adherentes que aquellas con ingresos inferiores a $500 €(\mathrm{OR}=$ $0,09, p<0,001$ ). El resto de las variables demográficas (situación laboral, familia con $\mathrm{VIH}$, personas con las que convive) y clínicas (efectos secundarios, número de principios activos y de medicamentos) no mostraron efectos significativos (tabla 3 ).

Tabla 3. Efecto de las variables demográficas y clínicas en la no ADH al TAR

\begin{tabular}{|c|c|c|c|c|}
\hline & \multicolumn{2}{|c|}{ Análisis Univariado } & \multicolumn{2}{|c|}{ Análisis Multivariado } \\
\hline Variables demográficas & OR (IC 95\%) & p-valor & OR (IC 95\%) & $p$-valor \\
\hline Edad & $0,97(0,92-1,01)$ & 0,130 & $0,92(0,85-0,99)$ & $0,032^{*}$ \\
\hline $\begin{array}{l}\text { Nivel de estudios } \\
\text { Sin estudios/Primarios }\end{array}$ & Ref. & & & \\
\hline Secundaria/Bachiller & $0,56(0,22-1,44)$ & 0,228 & $0,60(0,17-2,13)$ & 0,430 \\
\hline Universitarios & $0,10(0,01-0,90)$ & $0,040^{*}$ & $0,36(0,01-0,78)$ & $0,023^{*}$ \\
\hline Ingresos propios & & & & \\
\hline Menos de $500 € /$ mes & Ref. & & & \\
\hline $500-700 € / \mathrm{mes}$ & $0,40(0,13-1,26)$ & 0,117 & $0,75(0,18-3,07)$ & 0,691 \\
\hline Más de $700 € /$ mes & $0,09(0,03-0,31)$ & $<0,001^{* * *}$ & $0,16(0,03-0,86)$ & $0,033^{*}$ \\
\hline
\end{tabular}

Nota: OR: odds ratio. ${ }^{*} p<0,05$ Ref $=$ Valor de referencia

\section{Resultados cualitativos}

Del análisis de las entrevistas semiestructuradas realizadas a una submuestra de mujeres con problemas de adhesión al tratamiento emergen cuatro categorías principales de análisis.

\section{Factores personales}

Los factores personales que influyen en la adherencia al tratamiento están relacionados con las características sociodemográficas (tabla 1) y los aspectos cognitivo-emocionales. Estos aspectos permiten contextualizar socialmente el fenómeno de estudio y aporta información relevante para comprender la experiencia individual de cada participante, aunque encontramos aspectos comunes que se destacan a continuación.

Los aspectos cognitivo-emocionales, están altamente relacionados con los factores interpersonales y la aparición de procesos de autoestigmatización. Los sentimientos y emociones derivados del diagnóstico positivo de VIH y las vivencias asociadas limitan las relaciones interpersonales y alteran la cotidianidad de las participantes. El sentimiento principal entre las participantes es el miedo, tanto a contagiar a terceras personas, como al progreso de la propia enfermedad, y a que se conozca la situación de seroestatus, lo que provoca el ocultamiento de cualquier actividad que se pueda asociar al $\mathrm{VIH}$, incluyendo la recogida en las farmacias hospitalarias de los TAR. También emergen sentimientos de rencor, rabia, rechazo, traición o enfado (tabla 4). 
"Tienes que ir con el macutillo de los medicamentos escondido en el fondo de la maleta, para que no te vea nadie tomarte los medicamentos por si te preguntan: “¿Eso que te tomas qué es lo que es?” MVIH7

"El cartón (la caja del TAR) tampoco puedo dárselo a cualquiera porque en la caja te lo pone y sabes tú que el móvil enseguida...te lo sacan todo" MVIH13

Tabla 4. Sentimientos asociados al VIH

\section{Miedo}

\begin{tabular}{|c|c|}
\hline A la enfermedad & $\begin{array}{l}\text { "Yo desde el principio de esto no lo sabía, tenía miedo como mucha gente } \\
\text { tiene" MVIH5 }\end{array}$ \\
\hline $\begin{array}{l}\text { Al progreso de la } \\
\text { enfermedad }\end{array}$ & $\begin{array}{l}\text { "El pensar que yo no me voy a poder valer por mí misma me condiciona } \\
\text { muchísimo, o sea, me, no es que me dé miedo es que me aterra y quizás } \\
\text { lo sumas al secreto de decir: voy a estar enferma y no voy a poder decir } \\
\text { por qué" MVIH7 }\end{array}$ \\
\hline $\begin{array}{l}\text { A desvelar el } \\
\text { seroestatus }\end{array}$ & $\begin{array}{l}\text { "Mi hijo no lo sabe porque todavía es pequeño ¿se lo voy a decir? ¿No se } \\
\text { lo voy a decir? ¿Cómo se lo voy a decir? ¿Cómo le va a afectar? Cuando } \\
\text { yo me ponga enferma por cualquier cosa, no sé, o se agrave mi } \\
\text { enfermedad ¿qué voy a decirle?" MVIH7 }\end{array}$ \\
\hline $\begin{array}{l}\text { A contagiar a } \\
\text { otras personas }\end{array}$ & $\begin{array}{l}\text { "Tengo mucho cuidado con ella (mi hermana) en ese aspecto, porque ella } \\
\text { cualquier cosa que vea mía la está cogiendo. Por ejemplo, mi cepillo de } \\
\text { dientes, mi cuchilla...en el baño" MVIH1 }\end{array}$ \\
\hline $\begin{array}{l}\text { Al futuro y la } \\
\text { muerte }\end{array}$ & $\begin{array}{l}\text { "Lo primero que pregunté fue: “¿Pero me voy a morir?” MVIH2 } \\
\text { "Donde más se centran mis miedos es en el futuro, en el qué va a ser de } \\
\text { mí el día de mañana” MVIH7 }\end{array}$ \\
\hline
\end{tabular}

Resentimiento, rencor

“No me merezco, nada más porque (mi ex pareja) me ha jodido la vida a la hora de todo!” MVIH6

Rabia
"A mí me da rabia, porque es verdad. (...) hay gente que se lo busca y gente que no...) Yo nunca he tomado drogas y sin embargo tengo que acarrear con la enfermedad" MVIH8

\section{Rechazo}

"Yo oigo luego comentarios en la gente "Mira, mira, mira ese tiene SIDA (...) Pues veo que lo rechazan, a esas personas así las rechazan y les miran con mala cara" MVIH9

\section{Traición}

"No me podía imaginar semejante cosa, que eso pudiera haber pasado en mi casa, ni en él; bueno, en él (mi marido) sí, ya sí pensé que sí" MVIH12

"No sé nada porque yo fui totalmente engañada (...) Hasta la madre lo sabía y no decían nada" MVIH3

\section{Enfado}

"Entonces ya me dijo la doctora, me hicieron todo y yo me enfadé con él (mi marido), con mi suegra también" MVIH15

\section{Factores interpersonales}

Los principales factores interpersonales que tienen una incidencia negativa sobre la adherencia a los TAR son el apoyo sociofamiliar, autoestigma y estima sociofamiliar percibido.

El apoyo sociofamiliar puede ser un factor favorecedor de la adherencia al tratamiento cuando es positivo: 
"Vino mi primo de Madrid para contarme que tenía VIH y para decirme que tenía que tomarme una medicación (...). "Te tienes que tomar una medicación y llevar una vida normal y digo: ¡Ah, pues ya está!" tomarme una medicación (...) me llevaron a una Asociación a Murcia para informarme y bien" MVIH2

En este sentido el apoyo y la comprensión dentro de la pareja evita situaciones de ocultamiento reduciendo el nivel de autoestigma y normalizando el proceso de enfermedad:

"Quien realmente más me apoyó fue mi pareja en todos los sentidos: En decirme, en aconsejarme, en que no me dejaba ni un segundo, en apoyarme con el tratamiento" MVIH1

Aunque también puede funcionar como un factor perjudicial para la adherencia cuando es negativo influyendo directamente sobre la estabilidad emocional de las participantes y suponiendo en ocasiones un incentivo para ocultar el seroestatus, aunque suponga problemas para recoger la medicación:

"Buscar apoyos...es algo que no puedes (...). No puedes hablar con todo el mundo, ni abiertamente ni buscar ayuda, es mejor que no sepan" MVIH7

"Por tema de trabajo, porque yo prácticamente no puedo...sí que puedo decir "voy a ir al médico" pero cuanto menos me ausente pues parece que tienes que dar menos explicaciones (...) Por mi profesión, porque yo atiendo al público, entonces cuanto menos sepa la gente mejor" MVIH11

Por otro lado, los procesos de etiquetado y de asimilación de creencias y prejuicios relativos al VIH/SIDA tanto por parte de las mujeres infectadas como por sus entornos sociales, familiares y laborales afecta de forma directa y negativa al mantenimiento de una adherencia optiman al TAR. Las creencias de que todas las personas rechazan o rechazarían a otra persona por su seroestatus, empuja a las mujeres con el VIH/Sida a buscar estrategias para enmascarar todas las situaciones que tienen que enfrentar con relación a su enfermedad y el TAR.

"Cada vez que vengo a sacarme sangre tengo que inventarme algo (...). Cada vez que vengo a por medicinas hay que inventarse algo (...). Si cada vez que vienes al médico tienes que inventarte algo" MVIH7

\section{Factores relativos a la enfermedad del VIH/SIDA}

La aceptación de la enfermedad y la actitud hacia la misma determina en gran medida la adherencia al TAR, pero también se relaciona de forma directa con la adquisición de hábitos de autocuidado y cuidados hacia el entorno que complementan a los tratamientos farmacológicos.

Algunas participantes se han adaptado a vivir con la enfermedad a pesar de haber desarrollado actitudes de defensa hacia los prejuicios sociales que configuran el autoestigma y el estigma sociofamiliar y sociolaboral percibido. Esto las lleva en ocasiones a invisibilizar la enfermedad, minimizarla e incluso tratar de olvidar que tienen el VIH: 
"Hay cosas peores y peores quiero decir, en plan que hay personas que no pueden ni moverse ni nada" MVIH5

"Yo creo que me he adaptado a ella (a la enfermedad del VIH) (...). Pues hasta hoy día voy bien. Yo lo tengo asimilado" MVIH1

El estado de aceptación de la enfermedad para algunas participantes y de resignación para otras les conduce a incorporar nuevos hábitos de vida, inducidos por el consejo profesional, para mantener el estado de salud:

Autocuidados en la alimentación: "Intento alimentarme bastante bien, tomo vitaminas y por eso siempre he dicho de trabajar, porque trabajando uno tiene más ganas" MVIH1

Autocuidados de salud mental "Muchas veces cojo yo "mi motico" y me voy para el campo a pasearme o me voy a ver tiendas por distraerme, por no pensar, por no pensar" MVIH9

Revisiones médicas, analíticas y farmacológicas: Yo he seguido con mis analíticas" (...) Yo vengo a los médicos sola, me hago las pruebas y vengo sola (...) La del tórax, también me sale bien, la de los huesos me sale bien, si lo tengo todo bien, nada más que "eso está ahi "y hay que ir mirándolo" MVIH8

Cuidados de la sexualidad: "Ahora yo lo sé que esto no es... igual que hay que cuidarse de relaciones sexuales como cualquiera otras enfermedades que se pillan mucho más" MVIH5s

Estos hábitos rutinarios también están asociados al cuidado de las personas del entorno, principalmente para evitar la trasmisión de la enfermedad.

Cuidados hacia la familia: "También, se la hicimos (la prueba del VIH) a mi nene, pero le salió negativa al crío (...) Tengo una nena que está bien, que le he hecho las pruebas y está bien" MVIH8

Cuidados hacia los profesionales sanitarios: "Yo cuando voy a un médico lo primero que le digo es eso (que tengo el $\mathrm{VIH}$ ), al dentista y todo, sí, que lo primero, eso sí, siempre a ellos le digo" MVIH15

Por el contrario, las participantes que no aceptan la enfermedad desarrollan un afrontamiento negativo de la infección por $\mathrm{VIH}$. Esto les conduce a no desarrollar actitudes de autocuidado necesarias para afrontar la adherencia al tratamiento de una forma eficaz:

"Yo nunca le he aceptado" (...). "Es difícil de aceptarlo (...). Los primeros tiempos que yo estuve con eso un año, fue encerrada en la casa, pero ni la ventana abierta; todo totalmente cerrado" MVIH1

"No, aceptarla (La enfermedad del VIH) no la voy a aceptar nunca, porque no me la merezco, porque yo no la he buscado" MVIH6 


\section{Factores relativos al TAR}

Del grado de cumplimiento terapéutico del TAR depende el pronóstico y la calidad de vida. En este sentido se analizaron como factores relativos al TAR la información recibida sobre la importancia del tratamiento y de la adhesión al mismo, además de la actitud frente al TAR y percepción de su eficacia.

De este modo encontramos que la mayor parte de las participantes manifiesta haber recibido información de profesionales cualificados sobre el TAR, la importancia de una buena adherencia y las consecuencias, sobre el progreso de la enfermedad, asociadas a una baja o nula adherencia.

"La doctora me dijo: ...tendrás que tomarte una medicación, que esa medicación será tu vida (...). Si tú llevas ese tratamiento bien llevado... la posibilidad de vida es un poco más larga (...). Yo ya me había informado muy bien sobre la enfermedad sobre lo que surge cuando haces ciertas cosas, sobre si no te tomas la medicación, qué pasa paso por paso, en fin, de todo" MVIH3

Aunque también existe un caso que informa no haber recibido información suficiente sobre la dosificación y pautas del tratamiento, lo cual la llevó a cometer errores de autoadministración TAR.

"Cuando empecé con las pastillas, la primera vez que me las tomé no me explicaron cómo me las tenía que tomar (...) iYo me las tomé todas del tirón, yo me puse malísima con unas fiebres que para qué!" MVIH2

Además, la información recibida por las participantes favorece la actitud positiva frente al TAR y percepción de la eficacia del tratamiento. En este sentido la mayoría de las participantes refieren confiar en el TAR y percibir la eficacia del mismo:

"Soy consciente de que sin esa medicación no estaría como estoy (...). Yo estoy contenta con que voy muy bien, porque me lo dice la doctora, y aparte de la doctora, veo la analítica y sé que voy bien, porque la defensa ha subido bastante" MVIH1

Pero, aunque la percepción de la eficacia y la actitud frente al TAR es positiva para la mayoría de las participantes y el tratamiento es asumido como responsable de su bienestar a pesar de la enfermedad, en algunos casos se observan declaraciones contradictorias respecto a la $\mathrm{ADH}$ al TAR basadas en afirmaciones relacionadas retrasos en el horario de dosificación del medicamento, en la existencia de un remanente de pastillas y olvidos esporádicos en la toma de la medicación.

Dosificación incorrecta del medicamento: “(...). Cuando tomo, pues retraso un poco mi medicamento de su hora normal por no mezclar realmente con la bebida, pero nunca dejo de tomarla, ni un día lo dejo" MVIH1

Remanente de medicación: "El tratamiento lo llevo bien, o sea, que yo me lo tomo (...). Hay meses que vengo y que no vengo porque como tengo pastillas de sobra digo: “¿Para qué voy a echar el viaje? (...). Mi pastilla todas las noches y ya está, mi vida normal..." MVIH13

Olvidos en la toma de medicación: "Lo del medicamento seguí tomando. Ya me dijo mi doctora que tengo que seguir todo largo y que no debo de dejar de tomar, tengo 
que seguir al pie de la letra (...). Pues sigo así, aunque a veces me olvido y me vuelvo a tomar, así, pero sigo ahí” MVIH15

Otro factor importante cuando hablamos de adherencia a los TAR son los efectos secundarios y la simplificación de los tratamientos. En este sentido, podemos apreciar como la reducción del número de pastillas diarias favorece la adherencia: " $A$ lo primero te tenías que tomar hasta doce pastillas, se me olvidaba, ahora gracias a Dios con una tienes bastante (...) A mí no me hace efectos secundarios, nada y ya te digo, yo lo tengo indetectable (Carga viral)" MVIH8. Al igual que los efectos secundarios asociados al tratamiento suponen una barrera frente a una correcta adherencia: "Por la mañana me levanto bastante mal, se me suben unos ácidos que no veas, y yo le comentaba a la doctora que no podía seguir así, que estuve 2 - 3 días sin tomar la medicación porque no toleraba” MVIH1

\section{DISCUSIÓN}

Conocer el diagnóstico de seropositividad, crea un fuerte impacto emocional, produciendo en las mujeres una situación de shock, negación, sorpresa y miedo. Este impacto limita en gran medida relaciones interpersonales y altera la cotidianidad de las participantes. De los sentimientos que se instalan en la vida de las entrevistadas destaca el miedo a lo desconocido de la enfermedad, a la evolución de la misma, al descubrimiento de su seroestatus, a afrontar el futuro, y el medio a contagiar a terceras personas. En este sentido el impacto emocional, la angustia psicológica y los síntomas depresivos que se desarrollan durante la enfermedad, se asocian con la disminución de la $\mathrm{ADH}^{(11)}$.

Otro de los elementos destacados por las participantes del estudio es el estigma y el autoestigma, los cuales se asocian a una baja $\mathrm{ADH}^{(20)}$. Y aunque el nivel de estigma no está asociado al género, en las mujeres suele existir una presencia mayor de autoestigma $^{(20)}$. La condición de seropositividad que por desconocimiento se relaciona con conductas consideradas inmorales (promiscuidad o consumo de drogas) hace que las mujeres presenten estigma percibido de amigos, familia y profesionales de la salud(21). Por este motivo, algunas mujeres ven cuestionada su reputación, y se ven forzadas a aclarar que no tienen ese perfil. En las participantes del estudio el $79,1 \%$ contrajeron la enfermedad por vía sexual relacionado con que su pareja ocultó su estatus serológico. Estos datos reflejan una mayor vulnerabilidad biológica y social de las mujeres para infectarse con el $\mathrm{VIH}^{(19)}$. Además, las mujeres que viven con VIH/SIDA también presentan vulnerabilidad sociolaboral debido a las situaciones de discriminación relacionadas con la vulneración de la confidencialidad de su seroestatus a pesar de que en España existe cobertura legal(22). Estas situaciones y el estigma en el ámbito laboral percibido por las participantes, genera situaciones de ocultación de la enfermedad, miedo a ser despedidas, situaciones estresantes ligadas a lesiones en el ámbito laboral, ocultar la medicación, las citas médicas o el miedo a tomar el TAR en público, dificultando en gran medida la $\mathrm{ADH}^{(23)}$.

Estas situaciones producen un alto sufrimiento psicosocial en las mujeres seropositivas y el estigma relacionado con el $\mathrm{VIH}$, perpetúa el aislamiento y la soledad, como refugio para ocultar su seroestatus ${ }^{(11)}$, lo que supone un obstáculo para iniciar relaciones y generar redes sociales de apoyo. 
El apoyo social es reconocido como un factor muy favorable para la adherencia y garante de una mejor calidad de vida para las personas que padecen la enfermedad del VIH/Sida, convirtiéndose en un aspecto esencial para mejorar las habilidades de afrontamiento y compromiso frente a la $A D H$ a los $\operatorname{TAR}^{(24)}$. En las participantes del estudio el apoyo social, familiar y laboral ha sido descrito como insuficiente 0 inexistente, lo que puede ser uno de los elementos precipitantes del incumplimiento terapéutico del 59,3\%. Dentro del apoyo social, la convivencia positiva mejora la vivencia y aceptación de la enfermedad y como consecuencia la ADH al TAR. Sin embargo, la convivencia negativa a nivel comunitario y familiar compromete la ADH por la ruptura con el entorno social y las dificultades dentro del microsistema familiar(25). Razón por la cual, la atención sociosanitaria debe centrar sus esfuerzos no solo en el individual sino también en su entorno social ${ }^{(6)}$.

Queda patente la necesidad de establecer estrategias para favorecer y/o mejorar $\mathrm{ADH}$, aplicando la perspectiva de género para evitar el sesgo en la asistencia sanitaria(26) y estableciendo programas centrados en la mejora de la autoestima y el fortalecimiento de la actitud ante la enfermedad a través del apoyo emocional( ${ }^{(27)}$.

\section{Limitaciones del estudio}

El tamaño de la muestra puede ser un factor limitante para la generalización de los resultados. Por ello en la fase cuantitativa se utilizaron y cruzaron los resultados de distintos instrumentos para la confirmación de los resultados. Otra limitación de la fase cuantitativa es que el cuestionario SMAQ presenta la limitación el recuento y la predisposición a agradar(14,28). Mientras que el registro de farmacia sobrestima la adherencia dado que asume que el paciente toma la medicación que recoge. Si bien, la combinación de ambos métodos permite contrastar de forma aceptable el grado de adherencia ${ }^{(29)}$. Del mismo modo en la fase cualitativa tampoco es posible descartar cierto sesgo de deseabilidad social, donde las participantes pudieron orientar sus respuestas para dar una buena imagen de sí mismas. Principalmente amparado en los procesos de autoestigma que se describe en los resultados. Si bien existió una relación de confianza entre investigadora y participantes debido a que era personal de la farmacia y conocía la situación de adherencia de las participantes lo cual facilitó que hablasen más abiertamente de motivaciones personales y de género ante la adherencia al tratamiento.

\section{Implicaciones para la práctica clínica}

A nivel general los cuidados de enfermería no deben limitarse al plano biológico y social, sino abarcar también el existencial, con el fin de respetar la dignidad de las pacientes y ayudar a compensar el déficit de cualquier carencia de salud. En este sentido los cuidados a las mujeres infectadas con VIH/SIDA, deben orientarse hacia el desarrollo de procesos educativos y orientativos con enfoque de género y cultural para abordar aquellos factores psicosociales del proceso de adherencia. El abordaje de los determinantes sociales de la salud como el nivel socioeconómico y educativo, destacan como puntos a trabajar para mejorar la ADH. 


\section{REFERENCIAS}

1. ONUSIDA. Estadísticas mundiales sobre el VIH de 2017.Hoja informativa- Día Mundial del Sida 2018 [Internet]. 2018 [Citado el 24 de abril de 2020]. Disponible en: http://www.unaids.org/es/resources/documents/2018/UNAIDS_FautSheet

2. ONUSIDA. Informe mundial ONUSIDA, Informe sobre la epidemia mundial de Sida 2013 [Internet]. 2013[citado 20 de abril de 2020]. Disponible en: www.unaids.org/sites/default/files/media_asset/UNAIDS_Global_Report_2013_es_1.p df

3. Centro Nacional de Epidemiología- ISCIII. Vigilancia Epidemiológica del VIH y sida en España: Sistema de Información sobre Nuevos Diagnósticos de VIH y Registro Nacional de Casos de Sida. Área de Vigilancia de VIH y Comportamientos de Riesgo. [Internet] 2016 [citado 27 de abril de 2020]. Disponible en: www. Isciii/ISCIII/es/contenido/fd-servicios-cientifitecnicos/fdvigilancias-

alertas/fdenfermedades/fds-sida/pdfsida/Informe_VIH_SIDA_2016_def.pdf

4. European Centre for Disease Prevention and Control. Annual Epidemiological Report 2016- HIVIAIDS.Stockholm: ECDC. Stockholm: ECDC; 2016. Disponible en: http:// ecdc.europa.eu/en/healthtopics/aids/surveillance-reports/Pages/AnnualEpidemiological-Report-2016.aspx

5. Panel de expertos GeSida/ PNS. Recomendaciones de GeSida/Plan Nacional sobre el Sida respecto al tratamiento antirretroviral en adultos infectados por el virus de la inmunodeficiencia humana [Internet]. 2018. Disponible en: http://www.gesidaseimc.org/wp-content/uploads/2018/01/gesida_TAR_adultos_v3-1.pdf

6. Barroso J, Leblanc N, Flores D. It's not just the pills: A qualitative metasynthesis of HIV antiretroviral adherence research. J Assoc Nurses AIDS Care. 2017;28(4):462-78. doi: 10.1016/j.jana.2017.02.007.

7. Shubber Z, Mills EJ, Nachega J b., Al. E. Patient-reported barriers to adherence to antirretroviral theraphy: a systematic review and meta-analysis. PloS Med. 2016;13. doi: 10.1371/journal.pmed.1002183.

8. Puskas C, Hogg R. Unlocking adherence: is gender the key? Lancet. 2014;2(1). doi: 10.1016/S2352-3018(14)00033-2

9. Kanters S, Park JJ, K. C. Interventions to improve adherence to antiretroviral theraphy: a systematic review and network meta-analysis. Lancet HIV. 2017;4(1):3140. doi: 10.1016/S2352-3018(16)30206-5

10. UNAIDS. 5 Years since ICPD. 2017. Disponible en: http:// www.unaids.org/publications/documents/human/gender/newsletter.pdf.

11. Peltzer J, Ogawa L, Tusher S, Farnan R, Gerkovich M. A Qualitative Description of HIV- Infected African American Women's Experiences of Psychological Distress and Their Coping Strategies. J Ass Nurses AIDS Care. 2017;28(2):226-37. doi: 10.1016/j.jana.2016.09.010.

12. Rivera M, Varas N, Coriano D, Padilla M, Reyes M. Ellos de la calle, nosotras de la casa: el discurso patriarcal y las experiencias de mujeres que viven con el VIH/SIDA en Puerto Rico. In: La agenda emergente de las ciencias sociales Conocimiento, crítica e intervención (5o Congreso Nacional de Ciencias Sociales). Consejo Me. Madrid; 2015. p. 682-92.

13. Varela MT, Salazar IC, Correa D, Duarte C, Tamayo JA, Salazar AE. La evaluación integral de la adherencia al tratamiento en mujeres con VIH/SIDA: validación de un cuestionario. Rev Col Med,. 2009;40(4):386-97. doi: 10.15446/rsap.v17n4.38429 
14. Ibarra O, Morillo R. Lo que debes saber sobre la adherencia al tratamiento. Sociedad Española de Farmacia Hospitalaria (SEFH) [Internet]. Boehringer Ingelheim, editor. Badalona; $2017 . \quad$ Disponible en: www.sefh.es/bibliotecavirtual/Adherencia2017/libro_ADHERENCIA.pdf

15. Limaylla M, Ramos $N$. Métodos indirectos de valoración del cumplimiento terapéutico. Cienc e Investig. 2016;19(2).

16. Knobel H, Alonso J, Casado J, Collazos J, González J. Validation of a simplifield medication adherence questionnaire in a large cohort of HIVinfected patients: the GEMMA Study. AIDS. 2002;16(4):605-13. doi: 10.1097/00002030200203080-00012

17. Bonner, K., Mezochow, A., Roberts, T., Ford, N.,\& Cohn, J. (2013). Viral load monitoring as a toll to reinforce adherence: a systematic review. J Acquir Immune Defic Syndr. 64(1):74-8.

18. Panel de expertos GeSida/SPNS. Factores que condicionan el exito del tratamiento antirretroviral. En GeSida/PNS., Documento de consenso de Gesida/Plan Nacional sobre el sida respecto al tratamiento antirretroviral en adultos infectados por el virus de la inmunodeficiencia humana. Ministerio de Sanidad Servicios Sociales e Igualdad de España. Madrid; 2016. 82-86 p.

19. Asboe D, Aitken C, Boffito M, Booth C, Cane P. British HIV Association guidelines for the routine investigation and monitoring of adult HIV-1 infected individuals. HIV Med. 2011;13(1). doi: 10.1111/j.1468-1293.2011.00971.x

20. Li L, Lin C, Ji G. Gendered Aspects of Perceived and Internalized HIVRelated Stigma in China. Women Health. 2016;59(7):1031-43. doi: 10.1080/03630242.2016

21. Valencia- García D, Rao D, Strick L, Simoni J. Women's experiences with HIV - related stigma from health care providers in Lima, Peru:" I would rather die than go back for care". Heal Care Women Int. 2017;38(2):144- 158. doi: 10.1080/07399332.2016.1217863

22. Molero F, Fuster M. La influencia del prejuicio y la discriminación. Encuentro FIPSE sobre la investigación de la perspectiva social del VIH/Sida. FIPSE, editor. Asturias; 2006.

23. Knowlton R, Bohret A, Yang Cui WL, Chande G. Main partner factors associated with worse adherence to HAART among women in Baltimore Maryland: a preleminary study. AIDS Care. 2011;23(9):1102-10. doi: 10.1080/09540121.2011.554516

24. Caiola C, Barroso J, Sharron L. Black mothers Living with HIV picture the social determinants of health. J Ass Nurses AIDS Care. 2018;29(2):204-19. doi: 10.1016/j.jana.2017.09.011

25. Garibi C. La compleja relación violencia de género- sida. Un acercamiento a la violencia institucional como factor de vulnerabilidad de las mujeres ante un VIH. Sex salud y Soc. 2009;3:82-105. Disponible en: http://www.insp.mx/salud/index.html

26. Valls-Llobet C. Manifestaciones y medicalización del malestar en las mujeres. Consumo. Ministerio de Sanidad y Consumo (Observatorio de la Salud de la Mujer) y la Universidad Complutense de Madrid (Grupo de Investigación Estilos Psicológicos, Programa de formadores/as en perspectiva de género en salud. Madrid; 2005.

27. La Fauri M, Zíniga M. Mujeres colombianas viviendo con el VIH/Sida: Contextos, experiencias y necesidades de cuidados de enfermería. Enfer Glob. 2011;10(24):317-27. doi: 10.4321/S1695-61412011000400024

28. Pagès- Puigdemont $\mathrm{N}$, Valverde- Merino MI. Métodos para medir la adherencia terapéutica. ARS Pharm. 2018;59(3). doi:10.30827/ars. v59i3.7387 
29. Ortega Valin L. Adhesión al tratamiento Antirretroviral: Una actualización. In: 2o Seminario de Atención Farmacéutica (Grupo de trabajo de la SEFH) Libro de sesiones. Icono. Madrid; 2002. p. 178-90. 